\title{
МАТЕРІАЛОЗНАВСТВО
}

\section{УДК 539.43:669.141.25-026.56}

\author{
И. В. АКИМОВ ${ }^{1 *}$ \\ ${ }^{1 *}$ Каф. «Композиционные материалы и технологии», Запорожский национальный технический университет, \\ ул. Жуковского, 64, Запорожье, Украина, 69063, тел. +38 (061) 76983 91, эл. почта tmzntu@gmail.com, \\ ORCID 0000-0001-6076-0149
}

\section{ПОВЫШЕНИЕ МЕХАНИЧЕСКИХ СВОЙСТВ ЛИТОЙ ГРАФИТИЗИРОВАННОЙ СТАЛИ}

Цель. Благодаря наличию многих ценных свойств (низкая себестоимость, высокие технологичность и демпфирующая способность, теплопроводность, жидкотекучесть и др.), графитизированные чугуны находят широкое применение для деталей, работающих в условиях статических и циклических нагрузок, в условиях износа - при сухом трении и в условиях агрессивных сред - при повышенных температурах. В то же время, по причине значительного содержания графитной фазы в структуре, чугуны обладают сравнительно низкими механическими свойствами. В этой связи обращают на себя внимание графитизированные стали, особенность которых заключается в наличии графитовых включений в структуре, придающих этим материалам специфические свойства чугуна. Но, в отличие от чугунов, содержание графита в них в 2-3 раза меньше, что положительно сказывается на показателях механических и служебных свойств. Данная работа посвящена оптимизации состава литой графитизированной стали, обладающей высокими показателями механических свойств. Методика. В работе использовали метод планирования эксперимента, на основании которого выплавляли опытные сплавы и исследовали их механические свойства. Полученные результаты подвергали регрессионной обработке, после чего получили зависимости влияния компонентов сплава на его свойства. Используя метод графической оптимизации, определяли оптимальный состав стали с высокими показателями механических свойств. Результаты. Установлено, что наиболее значительное влияние на прочность и циклическую выносливость графитизированных сталей оказывают углерод и кремний. В работе был предложен химический состав литой графитизированной стали с высокими показателями статической и циклической прочности. Научная новизна. С применением методов математического планирования эксперимента получены зависимости, описывающие влияние углерода, кремния и меди на показатели статической и циклической прочности и позволяющие оптимизировать составы графитизированных сталей. Практическая значимость. Использование графитизированных сталей оптимизированного состава в машиностроении позволит расширить их область применения с обеспечением повышения надежности и долговечности деталей, работающих в условиях как статических, так и циклических нагрузок.

Ключевые слова: графитизированная сталь; структура; механические свойства; оптимизация состава

\section{Введение}

Как известно, графитизированные стали представляют собой железоуглеродистые сплавы, в которых углерод частично находится в виде графитовых включений. Благодаря более низкому по сравнению с чугунами содержанию углерода $(1,2-1,8 \%)$ и, соответственно, графи- та, эти сплавы сочетают в себе, с одной стороны, положительные качества чугунов (высокая демпфирующая способность, низкая чувствительность к концентраторам напряжений, высокие технологические свойства, невысокая стоимость, и др.) $[1,11,18,17]$, с другой, более высокие по сравнению с чугунами механиче- 
ские свойства $[8,10,13]$. Детали машин, для которых графитизированные стали могли бы использоваться как конструкционные материалы (коленчатые валы, шатуны, сепараторы и вкладыши подшипников и т.п.) работают в достаточно разнообразных условиях нагружения, включающих как статические, так и циклические нагрузки с широкими диапазонами частот $[16,19]$. Так, по данным Пойды А. А. и Хуторянского Н. М. [14] частота рабочих колебаний коленчатого вала из высокопрочного чугуна ВЧ50-2 для дизеля ПД1М, несущего шесть цилиндровых масс и массу генератора, может достигать 22000 колебаний в минуту). Учитывая этот факт, можно сказать, что одним из определяющих факторов выбора для таких изделий материала является высокий уровень его статической и циклической прочности как при низких, так и высоких частотах нагружения. В то же время, сопротивление графитизированных сталей разрушению при циклических нагрузках, как альтернативного материала для указанных изделий, изучено недостаточно. Имеются лишь отдельные сведения по малоцикловой усталости [2] и циклической вязкости разрушения [15] при частоте нагружения, не превышающих 15 Гц.

В этой связи, исследование сопротивления разрушению графитизированных сталей при статических и циклических нагрузках в условиях высоких частот нагружения, как потенциального конструкционного материала для тяжелонагруженных изделий ответственного назначения, представляет научный и практический интерес.

\section{Цель}

Цель работы - оценка влияния углерода и кремния как элементов, наиболее сильно влияющих на процессы графитизации и меди, которая согласно [12] является элементом, способствующим графитизации вторичного цементита, улучшающим распределение графитовых включений и повышающим механические свойства граффити-зированных сплавов на формирование структуры металлической основы, графитной фазы и свойств графитизированных сталей. А также определение оптимального содержания указанных химических элементов для получения высоких показателей статической и циклической прочности исследуемых сталей.

\section{Методика}

Выплавку различных составов сталей проводили с использованием метода планирования эксперимента, где в качестве независимых переменных было выбрано содержание углерода $(0,5-1,9 \%)$ и кремния $(0,6-2,6 \%)$, а также меди $(0-4,0 \%)$. Содержание остальных химических элементов составляло: $\quad 0,60-0,70 \quad \% \quad \mathrm{Mn}$; $0,15-0,18 \% \mathrm{Cr} ; 0,22-0,25 \% \mathrm{Al}$ и до $0,02 \% \mathrm{~S}$ и $0,03 \%$ Р. В качестве зависимых переменных были приняты статическая $\sigma_{\text {в }}$ и циклическая $\sigma_{-1}$ прочности сплава. Использовав метод планирования эксперимента [4] в работе был реализован полный факторный эксперимент второго порядка $2^{3}$ (табл. 1), включающий в себя восемь основных опытов, а также опыты на «звездном» и нулевом уровнях.

Таблица 1

Table 1

\section{Центральный композиционный план $2^{3}$}

Central composite plan2 ${ }^{3}$

\begin{tabular}{|c|c|c|c|c|}
\hline \multirow{2}{*}{\multicolumn{2}{|c|}{$\begin{array}{c}\text { Интервал } \\
\text { варьирования и уровни } \\
\text { факторов }\end{array}$}} & \multicolumn{3}{|c|}{ Изучаемые факторы } \\
\hline & & $\begin{array}{c}X_{1} \\
(\mathrm{C}, \%)\end{array}$ & $\begin{array}{c}X_{2} \\
(\mathrm{Si}, \%)\end{array}$ & $\begin{array}{c}X_{3} \\
(\mathrm{Cu}, \%)\end{array}$ \\
\hline \multicolumn{2}{|c|}{$\begin{array}{c}\text { Нулевой уровень: } \\
\quad X_{0}=0\end{array}$} & 1,2 & 1,6 & 2,0 \\
\hline \multirow{2}{*}{$\begin{array}{c}\text { Интервал } \\
\text { варьирования }\end{array}$} & 1,0 & 0,4 & 0,6 & 1,2 \\
\hline & 1,682 & 0,7 & 1,0 & 2,0 \\
\hline \multicolumn{2}{|c|}{$\begin{array}{c}\text { Нижний уровень: } \\
\quad X=-1,0\end{array}$} & 0,8 & 1,0 & 0,8 \\
\hline \multicolumn{2}{|c|}{$\begin{array}{c}\text { Верхний уровень: } \\
X=+1,0\end{array}$} & 1,6 & 2,2 & 3,2 \\
\hline \multirow{2}{*}{$\begin{array}{c}\text { Звездные } \\
\text { точки }\end{array}$} & 1,682 & 0,5 & 0,6 & 0 \\
\hline & $=1,682$ & 1,9 & 2,6 & 4,0 \\
\hline
\end{tabular}

По составленной матрице планирования в индукционной печи выплавляли опытные сплавы, которые разливали в сухие песчаноглинистые формы. Из полученных слитков изготавливали испытательные образцы и исследовали их механические свойства. Временное сопротивление $\sigma_{\text {в }}$ и относительное удлинение $\delta$ определяли в соответствии с ГОСТ 1497-84. Испытания на усталость сталей при высокочастотном знакопеременном нагружении проводи- 
ли, руководствуясь ГОСТ 25.502-79, на исследовательских комплексах Белорусского государственного технологического университета при частоте 18,0 кГц, с определением характеристик сопротивления металла формированию очагов разрушения [5]. Фазовый состав и размер структурных элементов сталей определяли, используя методики количественной металлографии [6]. Полученные результаты подвергали регрессионной обработке, в результате чего получали зависимости влияния компонентов сплава на его свойства. Используя метод графической оптимизации, предложенный Ковшовым В.Н. [9], определяли оптимальный состав стали с высокими показателями механических свойств.

\section{Результаты}

Результаты металлографического анализа полученных сплавов в литом (не термообработанном) состоянии показали разнородность микроструктур, главным образом, в зависимости от содержания углерода и кремния [3].

Для улучшения структуры и свойств опытных сталей полученные отливки подвергали закалке (нагрев до $860{ }^{\circ} \mathrm{C}$, выдержка 1 час, охлаждение в масло) с последующим средним отпуском (500 ${ }^{\circ} \mathrm{C}, 2$ часа). Такая термообработка способствовала образованию сорбита отпуска в структуре металлической основы и практически не изменила количество, форму и распределение графитовых включений в ней.

Из полученных термообработанных слитков вырезали образцы для механических испытаний, результаты которых приведены в табл. 2. Их анализ показал, что все исследуемые характеристики проявляли значительную чувствительность к структуре. Так наиболее высокими показателями статической и циклической прочности характеризовалась сталь, содержащая по варьируемым элементам $0,72 \% \mathrm{C}$; $2,17 \% \mathrm{Si}$ и 3,25\% $\mathrm{Cu}$ (см. табл. 2, вар. 7), что объясняется как благоприятной - компактной формой графитовых включений, так и мелкодисперсной сорбитной структурой, способствующей повышению прочностных характеристик [7]. Обращает на себя внимание сталь, обладающая наибольшей пластичностью (см. табл. 2, вар. 9). В ее структуре было наименьшее количество графитной фазы и наи- большее - высокопластичной ферритной фазы, что в целом способствовало повышению относительного удлинения $\delta$ до $22 \%$. Наиболее низкими показателями прочности и пластичности характеризовалась сталь вар. 10 (см. табл. 2), что можно объяснить наибольшим содержанием в ее составе углерода, а, следовательно, и графитной, не компактной фазы в структуре, снижающей механические свойства.

Регрессионная обработка полученных результатов механических свойств позволила получить ряд уравнений, описывающих зависимости механических свойств от содержания углерода, кремния и меди.

Таблица 2

Table 2

Механические свойства опытных сплавов

Mechanical properties of experimental alloys

\begin{tabular}{|c|c|c|c|c|c|c|}
\hline \multirow{3}{*}{ 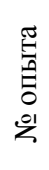 } & \multicolumn{6}{|c|}{ Химический состав } \\
\hline & \multicolumn{2}{|c|}{$\mathrm{C}, \%$} & \multicolumn{2}{|c|}{$\mathrm{Si}, \%$} & \multicolumn{2}{|c|}{$\mathrm{Cu}, \%$} \\
\hline & $\mathrm{p}$. & $\phi$. & $\mathrm{p}$ & $\phi$. & p. & $\phi$. \\
\hline 1 & 0,8 & 0,78 & \multirow{2}{*}{1,0} & 1,01 & \multirow{4}{*}{0,8} & 0,84 \\
\hline 2 & 1,6 & 1,54 & & 1,07 & & 0,85 \\
\hline 3 & 0,8 & 0,78 & \multirow{2}{*}{2,2} & 2,18 & & 0,92 \\
\hline 4 & 1,6 & 1,73 & & 2,29 & & 0,87 \\
\hline 5 & 0,8 & 0,74 & 10 & 1,01 & \multirow{4}{*}{3,2} & 3,17 \\
\hline 6 & 1,6 & 1,74 & & 1,04 & & 3,15 \\
\hline 7 & 0,8 & 0,72 & \multirow{2}{*}{2,2} & 2,17 & & 3,25 \\
\hline 8 & 1,6 & 1,78 & & 2,25 & & 3,19 \\
\hline 9 & 0,5 & 0,48 & & 1,66 & \multirow{4}{*}{2,0} & 1,90 \\
\hline 10 & 1,9 & 1,95 & & 1,66 & & 1,94 \\
\hline 11 & \multirow{5}{*}{1,2} & 1,23 & 0,6 & 0,62 & & 1,95 \\
\hline 12 & & 1,26 & 2,6 & 2,55 & & 2,09 \\
\hline 13 & & 1,23 & \multirow{3}{*}{1,6} & 1,61 & 0 & 0,02 \\
\hline 14 & & 1,21 & & 1,69 & 4,0 & 3,95 \\
\hline 15 & & 1,27 & & 1,65 & 2,0 & 2,01 \\
\hline
\end{tabular}




\begin{tabular}{|c|c|c|c|}
\hline \multirow{2}{*}{ 㕫营 } & \multicolumn{3}{|c|}{ Механические свойства } \\
\hline & $\sigma_{\mathrm{B}}, \mathrm{MПа}$ & $\delta, \%$ & $\sigma_{-1}, \mathrm{M \Pi а}$ \\
\hline 1 & 820 & 19 & 384 \\
\hline 2 & 760 & 12 & 315 \\
\hline 3 & 915 & 15 & 385 \\
\hline 4 & 778 & 8 & 312 \\
\hline 5 & 970 & 17 & 389 \\
\hline 6 & 880 & 10 & 322 \\
\hline 7 & 1280 & 12 & 409 \\
\hline 8 & 990 & 6 & 336 \\
\hline 9 & 720 & 22 & 361 \\
\hline 10 & 443 & 5 & 264 \\
\hline 11 & 874 & 15 & 384 \\
\hline 12 & 730 & 8 & 360 \\
\hline 13 & 745 & 14 & 355 \\
\hline 14 & 721 & 10 & 342 \\
\hline 15 & 887 & 12 & 358 \\
\hline
\end{tabular}

Примечание: p. и ф. - расчетный и фактический составы варьируемых элементов соответственно, согласно табл. 1.

После проверки адекватности моделей и перехода к натуральным переменным были получены уравнения второго порядка:

$$
\begin{gathered}
\sigma_{-1}=397+126 \mathrm{C}-76 \mathrm{Si}-7 \mathrm{Cu}-5 \mathrm{CSi}+\mathrm{CCu}+ \\
+6 \mathrm{SiCu}-83 \mathrm{C}^{2}+21 \mathrm{Si}^{2} ; \\
\sigma_{\mathrm{B}}=312+1029 \mathrm{C}-63 \mathrm{Si}+37 \mathrm{Cu}-144 \mathrm{CSi}-48 \mathrm{CCu}+ \\
+53 \mathrm{SiCu}-372 \mathrm{C}^{2}+52 \mathrm{Si}^{2}-4 \mathrm{Cu}^{2} ; \\
\delta=36,7-19,8 \mathrm{C}-2,3 \mathrm{Si}-\mathrm{Cu}+0,5 \mathrm{CSi}+ \\
+0,3 \mathrm{CCu}-0,2 \mathrm{SiCu}+3,4 \mathrm{C}^{2}-0,5 \mathrm{Si}^{2} .
\end{gathered}
$$

Проведенный графический анализ полученных уравнений показал, что кривые зависимости статической и циклической прочности от содержания углерода проходят через максимум в области его содержания $0,8-1,0 \% \mathrm{C}$.

О влиянии кремния и меди на показатели сопротивления статическому и усталостному разрушению можно сказать, что отдельное влияние этих элементов незначительно повышало пределы прочности и выносливости стали.

Для определения состава, обеспечивающего оптимальное сочетание свойств статической и циклической прочности графитизированной стали, выполняли графическую оптимизацию содержания углерода и меди при исходном содержании кремния $2,2 \%$. Для определения оптимального содержания указанных элементов был построен график двухмерных сечений поверхностей отклика по двухфакторному полиному, в который предварительно было введено наиболее желательное числовое значение исследуемых параметров: $\sigma_{\mathrm{B}}=1000-1200$ МПа и $\sigma_{-1}=1$ 000-1 200 МПа. Результатом оптимизации было определение зоны оптимальных содержаний углерода $0,8-1,1 \%$ и меди $3,0-3,2 \%$ (рис. 1, заштрихованная область).

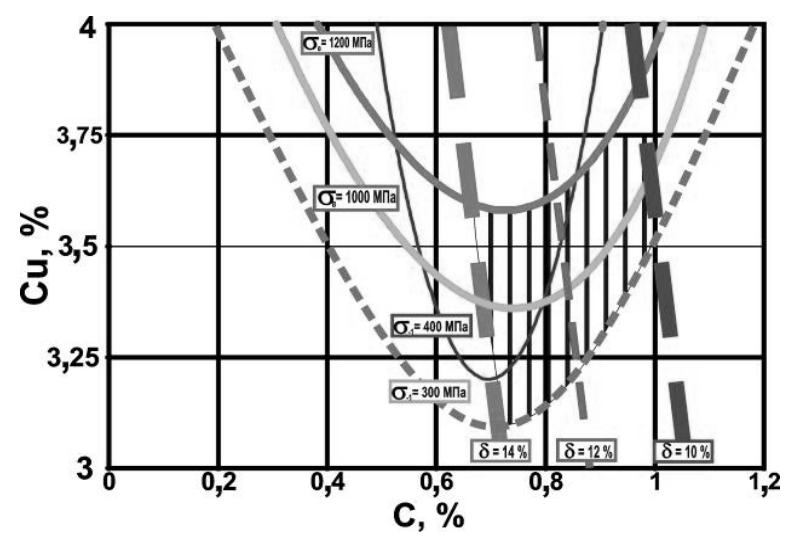

Рис. 1. Графическая оптимизация состава высокопрочной графитизированной стали по углероду и меди при $\mathrm{Si}=2,2$ \%

Fig. 1. Graphical optimization of the high strength of graphitized carbon steel and copper when $\mathrm{Si}=2,2 \%$

\section{Научная новизна и практическая значимость}

В работе с применением методов математического планирования эксперимента получены зависимости, описывающие влияние углерода, кремния и меди на показатели статической и циклической прочности, позволяющие оптимизировать составы графитизированных сталей. 


\section{Выводы}

Результаты проведенных экспериментов показали, что наиболее благоприятное сочетание свойств: $\sigma_{\mathrm{B}}=1000-1200$ МПа; $\delta=10-14 \%$; $\sigma_{-1}=300-400$ МПа имела графитизированная сталь состава: $0,8-1,0 \% \mathrm{C} ; 2,2-2,4 \% \mathrm{Si}$; 3,0-3,2\% Cu; 0,60-0,70\% Mn; 0,15-0,18\% Cr; $0,22-0,25 \% \mathrm{Al}$ и до $0,02 \% \mathrm{~S}$ и $0,03 \%$ Р. По показателям статической и циклической прочности ГС указанного состава превосходят высокопрочные чугуны марок ВЧ40-ВЧ50 и ряд марок углеродистых сталей.

\section{СПИСОК ИСПОЛЬЗОВАННЫХ ИСТОЧНИКОВ}

1. А.c. 1793001 СССР, МКИ С 22 С 38/34. Графитизированная сталь / И. П. Волчок, О. Б. Колотилкин, С. А. Уваров (СССР). - № 4910094 ; заявл. 11.02.91 ; опубл. 07.02.93, Бюл. № 5. - 2 с.

2. Акімов, I. В. Підвищення високотемпературної витривалості графітизованих сталей / I. В. Акімов, I. П. Волчок // FIDES. : Intern. Forum for the Development of Education and Science Proc. - Norway : Lulu Press Inc., 2010. - P. 61.

3. Акимов, И. В. Усталостное разрушение графитизированных сталей при высоких частотах нагружения / И. В. Акимов, И. П. Волчок // Стрво, материаловедение, машиностроение : сб. научн. трудов / ПГАСА. - Днепропетровск, 2014. - Вып. 74. - С. 66-71.

4. Босов, А. А. Математичне моделювання планування експериментів / А. А. Босов, В. В. Артемчук // Вісн. Дніпропетр. нац. ун-ту залізн. трансп. ім. акад. В. Лазаряна. - Дніпропетровськ, 2008. - Вип. 25. - С. 118-121.

5. Вакуленко, I. О. Втома металевих матеріалів в конструкціях рухомого складу / І. О. Вакуленко. - Дніпропетровськ : Маковецький, 2012. - 152 с.

6. Вакуленко, I. О. Структурний аналіз в матеріалознавстві / I. О. Вакуленко. - Дніпропетровськ : Маковецький, 2010. - 124 с.

7. Вакуленко, И. А. Морфология структуры и деформационное упрочнение стали / И. А. Вакуленко, В. И. Большаков. - Днепропетровск : Маковецкий, 2008. - 196 с.

8. Жураковский, В. М. Организация трансформируемой структуры и обеспечение заданных свойств графитсодержащей стали : автореф. дис. ... д-ра техн. наук : 05.02.01 / Жураковский Василий Максимилианович ; Белорус. политехн. ин-т. - Минск, 1985. - 40 с.

9. Ковшов, В. Н. Методические указания к постановке эксперимента при выполнении курсовых научно-исследовательских работ / В. Н. Ковшов. - Днепропетровск : НМетАУ, 1999. - 50 с.

10. Колмыков, В. И. Особенности формирования графитсодержащих диффузионных слоев при двухступенчатой нитроцементации конструкционных сталей / В. И. Колмыков, И. Н. Росляков, О. В. Летова // Технология металлов. 2008. - № 11. - C. 22-24.

11. Савченко, В. А. Термостойкость графитизированной стали / В. А. Савченко // Наука та прогр. трансп. Вісн. Дніпропетр. нац. ун-ту залізн. трансп. - 2014. - № 4 (52). - С. 95-100. doi: $10.15802 /$ stp2014/27333.

12. Сильман, Г. И. Влияние меди на структурообразование в чугуне / Г. И. Сильман, В. В. Камынин, А. А. Тарасов // Металловедение и терм. обработка металлов. - 2003. - № 7 . C. $15-20$.

13. Скворцов, А. И. Магнитные и демпфирующие свойства графитизированных сталей после изотермической закалки / А. И. Скворцов, Л. И. Агапова // Металловедение и терм. обработка металлов. - 1993. - № 5. - С. 9-10.

14. Пойда, А. А. Тепловозы. Механическое оборудование. Устройство и ремонт : учебн. для техн. школ / А. А. Пойда, Н. М. Хуторянский, В. Е. Кононов. - Москва : Транспорт, 1988. - 320 с.

15. Akimov, I. Wear resistance of graphitized steels / I. Akimov, S. Byelikov, I. Volchok // Archives of Metallurgy and Materials. - 2013. - Vol. 58. - Iss. 3. - P. 813-816. doi: 10.2478/amm-2013-0077.

16. Control of Carbides and Graphite in Cast Irons Type Alloy's Microstructures for Hot Strip Mills / S. V. Bravo, K. Yamamoto, H. Miyahara, K. Ogi // J. of Metallurgy. - 2012. - Vol. 2012. - P. 1-6. doi: $10.1155 / 2012 / 438659$.

17. Pat. US5830285 Japan, C21D1/26; C21D1/84, C21D8/06, C22C38/12, C22C38/60. Fine Graphite uniform dispersion steel excellent in gold Machinability, Cuttability and Hardenbility, and production method for the same / S. Katayama, T. Tarui, M. Toda, K.-I. Naito. - № US19960700355 ; filed 23.08.96, publ. 03.11.98.

18. Pat. 5,139,583 USA, C22C38/00. Graphite Precipitated hot-rolled Steel plate having workability and hardenability and method therefore / Y. Kawabata, M. Morita, F. Togashi. № US19920822649; filed 21.01.92; publ. 18.08.92.

19. Rounaghi, S.-A. Microstructure evolution in hypereutectoid graphitic steel / S.-A. Rounaghi, A. Kiani-Rashid // Intern. J. of Materials Research. - 2011. - Vol. 102. - Iss. 10. - P. 12421246. doi: 10.3139/146.110586. 


\section{B. AKIMOB ${ }^{1 *}$}

${ }^{1 *}$ Каф. «Композиційні матеріали та технології», Запорізький національний технічний університет, вул. Жуковського, 64, Запоріжжя, Україна, 69063, тел. +38 (061) 76985 32, ел. пошта tmzntu@gmail.com, ORCID 0000-0001-6076-0149

\section{ПІДВИЩЕННЯ МЕХАНІЧНИХ ВЛАСТИВОСТЕЙ ЛИТОЇ ГРАФІТИЗОВАНОЇ СТАЛІ}

Мета. Завдяки наявності багатьох цінних властивостей (низька собівартість, високі технологічні властивості та демпфуюча здатність, теплопровідність, рідиноплинність та ін.), графітизовані чавуни знаходять широке застосування для деталей, що працюють в умовах статичних і циклічних навантажень, в умовах зношування - при сухому терті та в умовах агресивних середовищ - при підвищених температурах. Проте, з причини значного вмісту графітної фази в структурі, чавуни володіють порівняно низькими механічними властивостями. У зв'язку з цим звертають на себе увагу графітизовані сталі, особливістю яких є наявність графітових включень у структурі, що надає цим матеріалам специфічних властивостей чавунів. Але, на відміну від чавунів, вміст графіту в них у 2-3 рази менше, що позитивно впливає на показники механічних та службових властивостей. Ця робота присвячена оптимізації складу литої графітизованої сталі 3 високими показники механічних властивостей. Методика. У роботі використовували метод планування експерименту, на підставі якого виплавляли сплави й досліджували їх механічні властивості. Отримані результати піддавали регресійній обробці, після чого отримували залежності впливу компонентів сплаву на його властивості. Використовуючи метод графічної оптимізації, визначали склад сталі з високими показниками механічних властивостей. Результати. Встановлено, що найбільш значний вплив на статичну та циклічну міцність графітизованих сталей здійснюють вуглець та кремній. У роботі був запропонований хімічний склад литої графітизованої сталі з високими показниками статичної та циклічної міцності. Наукова новизна. Із застосуванням методів математичного планування експерименту отримані залежності, що описують вплив вуглецю, кремнію та міді на показники статичної й циклічної міцності та дозволяють оптимізувати склад графітизованих сталей. Практична значимість. Використання графітизованих сталей оптимізованого складу в машинобудуванні дозволить розширити їх область застосування із забезпеченням підвищення надійності та довговічності деталей, котрі працюють як в умовах статичних, так і циклічних навантажень.

Ключові слова: графітизована сталь; структура; механічні властивості; оптимізація хімічного складу

\section{V. AKIMOV ${ }^{1 *}$}

${ }^{1 *}$ Dep. «Composite Materials and Technologies», Zaporizhzhia National Technical University, Zhukovskyi St., 64, Zaporizhzhia, Ukraine, 69063, tel. + 38 (061) 76985 32, e-mail tmzntu@gmail.com, ORCID 0000-0001-6076-0149

\section{INCREASING OF MECHANICAL PROPERTIES OF CAST GRAPHITIZED STEEL}

Purpose. Due to the presence of many essential properties (low prime cost, high manufacturability and damping ability, heat conductivity, fluidity and others), the graphitized cast irons are widely applied for parts operating under the conditions of static and cyclic loads, wear at dry friction and aggressive media at elevated temperatures. At the same time because of significant content of the graphite phase in the structure, the cast irons possess relatively low mechanical properties. Thereby the attention is drawn to graphitized steels, the peculiarity of which consists in the presence of graphite inclusions in the structure, which appoints specific cast iron's properties to these materials. But unlike cast irons, the graphite content in them is in $2 \ldots 3$ times lower and it affects positively on mechanical and service properties indices. This work deals with the optimization of the composition of cast graphitized steel, which has high mechanical properties indices. Methodology. The experimental design technique was used in this work. Alloys prototypes were smelted and their mechanical properties were investigated on the basis of these techniques. Findings were exposed to regression processing, and the dependences of the alloys components influence on its properties were obtained. By means of graphical optimization the optimal composition of steel with high mechanical properties indices has been determined. Findings. It has been established that carbon and silicon have the most significant influence on the strength and cyclic endurance of graphitized steels. The chemical composition of the cast graphitized steel with high static and cyclic strength indices was suggested in this work. Originality. With the use of 
mathematical experimental design techniques the dependences describing the influence of carbon, silicon and copper on the static and cyclic strength indices were obtained. They allow optimizing compositions of graphitized steels. Practical value. Using the graphitized steels with optimized composition in mechanical engineering will allow expanding their application areas along with providing reliability and durability of the parts operating under the conditions of static and cyclic loads.

Keywords: graphitized steel; structure; mechanical properties; optimization of the composition

\section{REFERENCES}

1. Volchok I.P., Kolotilkin O.B., Uvarov S.A. Grafitizirovannaya stal [Graphitized steel]. Inventor's Certificate USSR, 1993, no. 4910094, 2 p.

2. Akimov I.V., Volchok I.P. Pidvyshchennia vysokotemperaturnoi vytryvalosti hrafityzovanykh stalei [Improving the high-temperature resistance of graphitized steels]. FIDES. Intern. Forum for the Development of Education and Science Proc. Norway, Lulu Press Inc. Publ., 2010. P. 61.

3. Akimov I.V., Volchok I.P. Ustalostnoye razrusheniye grafitizirovannykh staley pri vysokikh chastotakh nagruzheniya [Fatigue failure of graphitized steels at high loading frequencies]. Stroitelstvovo, materialovedeniye, mashinostroeniye: sbornik nauchnykh trudov [Proc. of building, materials science, mechanical engineering]. Dnepropetrovsk, Pridneprovskaya gosudarstvennaya akademiya stroitelstva i arkhitektury Publ., 2014, issue 74, pp. 66-71.

4. Bosov A.A., Artemchuk V.V. Matematychne modeliuvannia planuvannia eksperymentiv [Mathematical modeling of experiments planning]. Visnyk Dnipropetrovskoho natsionalnoho universytetu zaliznychnoho transportu imeni akademika V. Lazariana [Bulletin of Dnipropetrovsk National University of Railway Transport named after Academician V. Lazaryan], 2008, issue 25, pp. 118-121.

5. Vakulenko I.O. Vtoma metalevykh materialiv $v$ konstruktsiiakh rukhomoho skladu [Fatigue of metallic materials in the construction of rolling stock]. Dnipropetrovsk, Makovetskyi Publ., 2012. 152 p.

6. Vakulenko I.O. Strukturnyi analiz v materialoznavstvi [Structural analysis in materials science]. Dnipropetrovsk, Makovetskyi Publ., 2010. 124 p.

7. Vakulenko I.A., Bolshakov V.I. Morfologiya struktury i deformatsionnoye uprochneniye stali [The morphology of the structure and strain hardening of steel]. Dnepropetrovsk, Makovetskiy Publ., 2008. 196 p.

8. Zhurakovskiy V.M. Organizatsiya transformiruyemoy struktury $i$ obespecheniye zadannykh svoystv grafitsoderzhashchey stali. Avtoreferat Diss. [Organization of transformed structure and ensuring the desired properties of steel graphite. Author`s abstract.]. Minsk, 1985. 40 p.

9. Kovshov V.N. Metodicheskiye ukazaniya $k$ postanovke eksperimenta pri vypolnenii kursovykh nauchnoissledovatelskikh rabot [Methodical instructions for the experiment during the course of research works]. Dnipropetrovsk, Natsionalna metalurhichna akademiia Ukrainy Publ., 1999. 50 p.

10. Kolmykov V.I., Roslyakov I.N., Letova O.V. Osobennosti formirovaniya grafitsoderzhashchikh diffuzionnykh sloyev pri dvukhstupenchatoy nitrotsementatsii konstruktsionnykh staley [Features of formation of graphite-bearing diffusion layers in two-stage carbonitriding structural steels]. Tekhnologiya metallov Metal Technology, 2008, no. 11, pp. 22-24.

11. Savchenko V.A. Termostoykost grafitizirovannoy stali [Heat resistance of graphitized steel]. Nauka ta prohres transportu. Visnyk Dnipropetrovskoho natsionalnoho universytetu zaliznychnoho transportu - Science and Transport Progress. Bulletin of Dnipropetrovsk National University of Railway Transport, 2014, no. 52, pp. 95-100. doi: 10.15802/stp2014/27333.

12. Silman G.I., Kamynin V.V., Tarasov A.A. Vliyaniye medi na strukturoobrazovaniye v chugune [The effect of copper on the structure formation in cast iron]. Metallovedeniye i termicheskaya obrabotka metallovMetallography and Heat Treatment of Metals, 2003, no. 7, pp. 15-20.

13. Skvortsov A.I., Agapova L.I. Magnitnyye i dempfiruyushchiye svoystva grafitizirovannykh staley posle izotermicheskoy zakalki [Magnetic and damping properties of graphitized steels after isothermal hardening]. Metallovedeniye i termicheskaya obrabotka metallov-Metallography and Heat Treatment of Metals, 1993, no. 5, pp. 9-10.

14. Poyda A.A., Khutoryanskiy N.M., Kononov V.Ye. Teplovozy. Mekhanicheskoye oborudovaniye. Ustroystvo $i$ remont [The locomotives. The mechanical equipment. The device and repair]. Moscow, Transport Publ., 1988. 320 p.

15. Akimov I., Byelikov S., Volchok I. Wear resistance of graphitized steels. Archives of Metallurgy and Materials, 2013, vol. 58, issue 3, pp. 813-816. doi: 10.2478/amm-2013-0077. 
16. Bravo S.V., Yamamoto K., Miyahara H., Ogi K. Control of Carbides and Graphite in Cast Irons Type Alloy's Microstructures for Hot Strip Mills. Journal of Metallurgy, 2012, vol. 2012, pp. 1-6. doi: $10.1155 / 2012 / 438659$.

17. Katayama S., Tarui T., Toda M., Naito K.-I. Fine Graphite uniform dispersion steel excellent in gold Machinability, Cuttability and Hardenbility, and production method for the same. 1998. No. US19960700355.

18. Kawabata Y., Morita M., Togashi F. Graphite Precipitated hot-rolled Steel plate having workability and hardenability and method therefore. 1992. No. US19920822649.

19. Rounaghi S.A, Kiani-Rashid A. Microstructure evolution in hypereutectoid graphitic steel. Intern. Journal of Materials Research, 2011, vol. 102, issue 10, pp. 1242-1246. doi: 10.3139/146.110586.

Статья рекомендована $к$ публикачии д.т.н., проф. И. А. Вакуленко (Украина); д.т.н., проф. А. В. Овчинниковым (Украина)

Поступила в редколлегию 30.03.2015

Принята к печати 05.06.2015 